\title{
Cuentos de hadas e infancia: la dialéctica entre tradición y modernidad
}

Adriana Marrero ${ }^{1}$

\section{Resumen}

Este artículo aborda el resurgimiento de los cuentos de hadas tradicionales en una década muy abundante de producción fílmica basada en sus historias, para la construcción de la identidad mediante el proyecto reflexivo del yo, característico de esta etapa de la modernidad. Teóricamente, se abreva de la idea de modernidad actual (GIDDENS e BECK, 1996) y las transformaciones de la educación concomitantes a la sociedad postindustrial (RIESMAN, 1964 e BAUMAN, 2001). Metodológicamente se vale de la hermenéutica para la interpretación de los significados objetivados que emanan de la trama de los filmes, para su discusión como potenciales orientadores de sujetos obligados a la individuación y a la formulación de planes de vida en contextos de alta incertidumbre. La hipótesis del trabajo consiste en que el desbalance entre un presente confuso y cacofónico, un futuro incierto y riesgoso hacia el cual proyectarse, y un pasado que brinda seguridad y sentido vital debido a la reelaboración y estilización de la tradición, juega un papel relevante en la explicación del regreso de cuentos de hadas clásicos, ya que ofrecen orientación normativa y contenidos educativos valiosos para los niños, que es necesario reafirmar.

Palabras Clave: Modernidad reflexiva, Cuentos de hadas, educación básica.

\section{Contos de fadas e infancia: a dialética entre tradição e modernidade}

\begin{abstract}
Resumo
Este artigo aborda o ressurgimento dos contos de fadas tradicionais em uma década farta de produção cinematográfica a partir de suas histórias, para a construção da identidade por meio do projeto reflexivo de si, característico desta fase da modernidade. Teoricamente, baseia-se na ideia de modernidade atual (GIDDENS e BECK, 1996) e nas transformações da educação concomitantes à sociedade pós-industrial (RIESMAN, 1964 e BAUMAN, 2001). Metodologicamente, utiliza a hermenêutica para a interpretação dos sentidos objetivados que emanam da trama dos filmes, para sua discussão como potenciais guias de sujeitos obrigados à indivisão e à formulação de planos de vida em contextos de grande incerteza. A hipótese do trabalho consiste em que o desequilíbrio entre um presente confuso e cacofônico, um futuro incerto e arriscado para o qual se projetar e um passado que dá segurança e sentido vital devido à reelaboração e estilização da tradição, desempenha um papel papel relevante na explicação da volta dos contos de fadas clássicos, uma vez que oferecem orientações normativas e valiosos conteúdos educacionais para as crianças, que é necessário reafirmar.
\end{abstract}

Palavras-chave: Modernidade reflexiva, Contos de fadas, Educação Básica.

\section{Fairy tales and childhood: the dialectic between tradition and modernity}

\begin{abstract}
The article addresses the resurgence of traditional fairy tales, on the occasion of a very abundant decade of film production based on their stories, for the construction of identity through the reflective project of the self, characteristic of this stage of modernity. Conceptually, it draws on theorizations about current modernity (GIDDENS e BECK, 1996) and the transformations of education concomitant to post-industrial society (RIESMAN, 1964 e BAUMAN, 2001). Methodologically, it uses hermeneutics for the interpretation of the objectified meanings that emanate from the plot and actions of some of the characters in the films, for their

\footnotetext{
${ }^{1}$ Doctora en Sociología por la Universidad de Salamanca, Magister en Educación (Ciep-IDRC), Licenciada en Sociología (Universidad de la República - Udelar) y Profesora de Educación Media (IPA). Profesora Titular Jubilada de Teoría Sociológica y Sociología de la Educación del Departamento de Sociología de la Universidad de la República e Investigadora del Sistema Nacional de Investigadores (ANII), Nivel II. Fue Profesora Titular y Directora del Departamento de Economía y Sociología de la Educación de la Facultad de Humanidades y Ciencias de la Educación, UdelaR. Orcid: https://orcid.org/0000-0003-0783-5775. E-Mail: adriana.marrero.fernandez@gmail.com.
} 
discussion as potential guides of subjects obliged to individuation and the formulation of life plans in contexts. Of high uncertainty. The hypothesis of the work consists in that the imbalance between a confused and cacophonic present, an uncertain and risky future towards which to project oneself, and a past that provides security and vital meaning due to the re-elaboration and stylization of tradition, plays a relevant role in explaining the return of classic fairy tales, as they offer normative guidance and valuable educational content for children, which needs to be reaffirmed.

Key Words: Reflexive Modernity, Fairy Tales, Elementary Education.

\section{Introducción}

La violencia contra niños sigue siendo un riesgo tan real como los peligros que los acechaban siglos atrás. Por ejemplo, consideremos los siguientes casos: Con ocho días de diferencia, a fines de 2017, dos niñas fueron secuestradas, abusadas y asesinadas. V.W., ${ }^{1}$ de 9 años, salió a buscar a su hermano, que estaba jugando fuera del hogar. Un vecino, de 22 años, se ofreció a acompañarla, pero la violó, la mató y, en complicidad con otro, tapó con piedras su cuerpo, que abandonó en un baldío. B.G., de 12 años, salió una mañana, a las 7:30, hacia la escuela. Tres días después, su cuerpo sin vida fue encontrado lejos. Había sido violada. Meses antes, lo mismo había sufrido F. R., que tenía 10 años cuando su entrenador de baby fútbol, un conocido de la familia lo secuestró, abusó sexualmente de él, lo mató, y se quitó la vida. Si bien pocas veces se llega al asesinato, el abuso de menores es un asunto que va cobrando mayor visibilidad y alarma en Uruguay, un país con 3,5 millones de personas, altamente alfabetizado, secular y urbano, esto es, moderno desde hace al menos un siglo.

Paralelamente, en los centros de producción simbólica, los cuentos de hadas tradicionales, cuyos mensajes podrían darse por perimidos, han cobrado nuevo vigor, de la mano de exitosas producciones cinematográficas. En la última década Disney lanzó varias películas basadas en cuentos infantiles clásicos, con pequeñas alteraciones, encarnados por actores reales: Into the woods (2014) que combina historias de varios cuentos, Cinderella (2015), Bella and the Beast (2017), y anuncia una nueva versión de Blancanieves y los siete enanos. Antes, Warner Brothers había estrenado Red Riding Hood (2011) y Estudios Universal, Snow White and the Huntsman (2012). Además de los cuentos clásicos de origen europeo, también han visto la luz filmes basados en historias orientales, como Aladdin (2019) y Mulán (2020), ambos de Disney. En una industria siempre atenta a la taquilla, esta apuesta

\footnotetext{
${ }^{1}$ Por cuestiones de ética profesional, el nombre de los niños aparecerá com iniciales.
} 
no puede sino entenderse en clave de oportunidad: los cuentos clásicos todavía tienen algo que decir a las nuevas audiencias.

El propósito de artículo es vincular ambos de fenómenos -los crímenes contra niños y el resurgimiento de los cuentos clásicos en filmes- a través de una lectura sociológica de la época en clave de modernidad tardía, reflexiva o radicalizada, tal como es teorizada en numerosos trabajos por autores como Giddens (1994), Beck (1996, 2001) y Bauman (2001), entre otros. El supuesto es que, como resultado de la aparición de mecanismos de desanclaje de la acción social, propios de esta etapa de la modernidad, de las referencias espacio temporales dentro de las que tiene lugar, se establece una nueva dinámica entre lo local y lo global, entre el pasado, el presente y el futuro, de modo que las experiencias locales y actuales de los sujetos, se vinculan de modo más o menos inmediato y reflexivo con fenómenos de alcance global cuyo significado se remonta al pasado (GIDDENS,1994:17). En la medida en que las historias generadas en sociedades europeas premodernas, lanzadas por la industria del cine para las nuevas audiencias globales, son resignificadas localmente, impactan en cómo las nuevas generaciones interpretan su experiencia y construyen reflexivamente su identidad, y proyectan su futuro. A la vez, son insumos valiosos para la elaboración de conocimiento pedagógico trasmitido a través de la escuela aún típica de la primera modernidad.

El artículo se desarrolla de la siguiente manera: Se mostrarán los aspectos teóricos básicos sobre los que se asienta la elaboración conceptual de la modernidad reflexiva, sobre el criterio de su pertinencia para el tema del que se trata: primero, en términos generales, y luego, en lo que respecta a las transformaciones en la educación. Luego, se expondrán las bases metodológicas para el análisis de los cuentos de hadas tales como aparecen presentados en filmes recientes. Finalmente, se propondrá un análisis de la continuidad, discontinuidad y resignificación de los roles femeninos y masculinos de los principales personajes en una etapa biográficamente crucial como es el despertar a la vida adulta y sexual, y el valor de estos cuentos como orientadores para la construcción y transmisión de pautas orientativas de la acción en el proceso de construcción de un proyecto reflexivo del yo de más largo aliento. Se concluirá mostrando el potencial educativo de mensajes que, más allá de lo alejado de sus orígenes en tiempo y espacio, tienen mucho que ofrecer en la empresa moderna de educar en la autopreservación. 
Modernidad tardía, tradición e Identidad del yo: el proceso de construcción de planes de vida y su conexión con el pasado

Como ha sido teorizado desde fines del siglo XX, la modernidad ha sufrido, por su propia dinámica, transformaciones tan profundas que ha merecido su redefinición teórica. Sociólogos como Anthony Giddens (1994), Ulrich Beck Beck (1996, 2011) o Sygmunt Bauman (2001), han preferido destacar el aspecto de continuidad más que de ruptura con la lógica moderna, -con un talante menos sombrío que el del relativismo posmoderno denominando a esta época "modernidad tardía, reflexiva y líquida respectivamente. Siguiendo a Giddens, (1994, 1995), esta nueva modernidad se distingue por la radicalización y universalización de los rasgos de la primera modernidad: racionalización creciente de las esferas de la vida y crecimiento exponencial del conocimiento experto, desvinculación de las identidades provenientes de criterios externos al sujeto y la necesidad de construcción reflexiva de la identidad propia, individuación, reflexividad institucional, globalización y nuevos modos de desanclaje entre los marcos de la acción humana en las coordenadas de espacio-tiempo.

Mientras que en Giddens (1994) la reflexividad de esta modernidad es institucional, para Beck Beck $(1996,2011)$ caracteriza a la época misma, y llama "modernidad reflexiva", a aquella que, en vistas de que el progreso puede convertirse en autodestrucción, se vuelve sobre sí misma, y se ve obligada a hacerse cargo de las consecuencias ambientales globales de la modernidad industrial, y a los riesgos generados por su dinámica. Surge así el concepto clave del autor, la "sociedad del riesgo", como una fase de desarrollo de la sociedad moderna en la que el ritmo de producción de riesgos políticos, ecológicos e individuales escapa, cada vez más, a las instituciones de control y protección de la sociedad industrial. (BECK, 1996, 2011). En el proceso de desvinculación con la primera modernidad, la modernidad reflexiva socava las formaciones a las que estaba vinculada la identidad industrial, tales como la clase social, la familia nuclear, los roles de género, las fábricas y lugares de trabajo, así como los prerrequisitos para el ideal de progreso y expansión industrial. Si la primera modernidad significó desvinculación de las estructuras tradicionales y vinculación con las industriales, esta etapa significa desvinculación de las industriales y revinculación a otras nuevas. (BECK et alt. 1994). 
Aunque la modernidad suponga la vivencia de un orden postradicional, eso no significa que la tradición haya desaparecido. La dialéctica entre tradición y modernidad es más compleja: "...la modernidad ha reconstruido la tradición a medida que la ha disuelto" (GIDDENS, 1996b, p. 76) y la ha conservado siempre que ha necesitado de ella para la legitimación del poder político, por ejemplo. Por tanto, "La modernidad es un orden postradicional sin que por ello haya que confundirlo con un marco social en el que las seguridades y hábitos de la tradición han sido reemplazados por la certidumbre del conocimiento racional" (GIDDENS, 1996, 35).

Mientras el principio de "duda radical" introducido por la razón crítica moderna ha impregnado todos los ámbitos de la vida y se ha institucionalizado a través del conocimiento experto, generando múltiples fuentes de autoridad, la tradición ha permanecido como "memoria colectiva" a través de la repetición y el ritual, a menudo transformada o resignificada, generando en el individuo una seguridad ontológica que el conocimiento experto no es capaz de ofrecer. Aunque no es imprescindible que la tradición sea antigua, su carácter integral, repetitivo y comunitario vincula al pasado con el presente, señalando a los sujetos, a través de una conexión emocional, un marco normativo en el que encuadrar su acción. A este campo pertenecen, entre otras manifestaciones culturales, los cuentos clásicos infantiles, o cuentos de hadas. Junto con las diversas fuentes de información derivadas del conocimiento experto, la tradicional es una más de las cuales el individuo, en esta etapa de la modernidad, ha de abrevar a fin de generar, como proyecto, una identidad del yo reflexivamente construida (GIDDENS, 1996b, 84).

\footnotetext{
La tradición, por tanto, es un medio de identidad. Personal o colectiva, la identidad exige significado: pero también supone del proceso constante de recapitulación y reinterpretación al que se ha aludido anteriormente. La identidad es la creación de constancia a lo largo de tiempo, ese poner en conjunción el pasado y el futuro anticipado. En todas las sociedades, el mantenimiento de la identidad personal y su conexión con identidades sociales más amplias es un requisito primordial de la seguridad ontológica. (...) La amenaza a la integridad de las tradiciones son muy frecuentemente, si no universalmente, experimentadas como amenazas a la integridad del yo (GIDDENS, 1996b, 104).
}

Al vaciarse de legitimidad las fuentes de sentido y de orientación normativa que generaban las estructuras premodernas, tales como el linaje heredado o el designio divino, el sujeto moderno emerge como artífice de su propio destino y víctima de su propia acción. 
Aprisionados en la jaula de hierro weberiana, en la alienación del trabajo obrero marxista o perdidos en la anomia durkheimiana, los primeros modernos se veían obligados a buscar un proyecto de vida emancipatorio no ya sólo de las ataduras del viejo orden feudal, sino de las tensiones generadas por la constricción compulsiva a un orden racionalizado y carente de sentido. Las ideologías políticas, la lucha de clases, o la integración un grupo social podían todavía ser fuente de sentido vital colectivamente compartido. La modernidad tardía ha profundizado la individualización propia de la modernidad, al institucionalizarla, y al convertir al individuo mismo -sin intermediación colectiva como la clase o la familia- en el referente de todos los derechos y de todas las responsabilidades por su propia vida. En una visión sombría, la individualización es "Un desequilibrio institucionalizado entre el individuo desincrustado y los problemas globales en una sociedad del riesgo global. (...) la necesidad de buscar soluciones biográficas a contradicciones sistémicas” (BECK Y BECK, 2003:31). El sujeto, condenado a la individualización, está obligado a vivir a su cuenta y riesgo. En la visión más luminosa de Giddens (1996), los sujetos deben formular un "proyecto reflexivo del yo", que mantenga la coherencia en las narraciones biográficas, a pesar de su continua revisión" y durante el cual, en contextos de múltiples posibilidades y restricciones, "se ven forzados a negociar los posibles estilos de vida entre una diversidad de opciones". Así, el plan de vida organizado reflexivamente, que normalmente asume la consideración de riesgos en base al conocimiento experto, es "un rasgo central de la estructuración de la autoidentidad" (GIDDENS, 1996:38).

En la modernidad tardía, la experiencia individual presente y la construcción del proyecto del yo, que tienen lugar en un presente confuso y opaco, signado por la búsqueda de orientación en medio de la pluralidad de fuentes derivada de la especialización del conocimiento experto, tienen sin embargo, como un ancla, su vinculación al pasado, a través de tradiciones que perviven por su reiteración sostenida, brindando marcos normativos de actuación y de significación, generando seguridad ontológica y cohesión social. Pero también, como contrapartida, una permanente conexión con el futuro. La proyección hacia delante de los planes de vida reflexivos trae permanentemente el futuro, de sí incognoscible, al presente, en el que asumen el carácter de "riesgo": "pensar en términos de riesgo es esencial para valorar hasta dónde es probable que los proyectos difieran de los resultados previstos" 
(GIDDENS, 1995:12).

La hipótesis central del trabajo consiste en proponer que este desbalance entre un presente confuso y cacofónico, un futuro incierto y riesgoso hacia el cual hay que proyectarse, y un pasado que brinda seguridad y sentido vital debido a su reelaboración y estilización en manos de sus "guardianes" en forma de tradiciones, juega un papel relevante en la explicación del regreso recurrente a los cuentos de hadas tradicionales. Aunque ya son ampliamente conocidos, adoptan un formato fílmico adecuado a las nuevas audiencias globales, pero no se sitúan ya en el campo de las películas de animación circunscriptas al público infantil, sino que, al adoptar el realismo clásico con actores de carne y hueso, revelan la intención de impactar a adolescentes y adultos jóvenes, igualmente necesitados de sentido y orientación. Con ello, claro está, podrán poner en discusión el desdibujamiento de los roles tradicionales de género propios de esta modernidad, pero contribuyen sin duda a poner sobre la mesa la discusión sobre la vigencia de criterios orientativos que se creían ya perdidos.

\section{La educación en la modernidad tardía}

En 1950 vio la luz una de las obras más influyentes de la sociología norteamericana del siglo XX: "La muchedumbre solitaria", de David Riesman (1964) quien, junto con Daniel Bell y otros teóricos de la época, fue pionero en detectar los cambios que había sufrido el carácter social estadounidense de la segunda postguerra mundial. Inspirado en la definición de Erich Fromm de la relación entre carácter y sociedad -los miembros de una sociedad deben “desear" comportarse como esa sociedad espera que lo hagan"- (RIESMAN, 1964, 17) el autor muestra cómo el carácter típico del sujeto moderno, fuertemente individualista, con una "dirección interna" que surge de normas y valores adquiridos durante su socialización, usados para expandir su esfera de acción a través de la exploración y la conquista, según el modelo weberiano del puritano, da paso a un sujeto menos seguro de sí, dependiente de la opinión de los demás y con valores fluctuantes. A este nuevo sujeto, Riesman le llamó "extradirigido".

El "intradirigido" no es un tradicionalista, típico de las sociedades premodernas. Aunque es portador de valores tradicionales, lo que da a su carácter una rigidez característica, aprecia la innovación y la libertad, y utiliza esos valores interiorizados para moverse en un ambiente que es cambiante, entre otras cosas, debido a su propia acción en el mundo. Nos 
referimos, claro está, a un tipo de comportamiento propio de la sociedad industrial, o de la primera modernidad.

Al igual que el resto de su tipología, Riesman (1964) asocia la aparición del extradirigido a cambios demográficos, en este caso, al declive del crecimiento poblacional y la aparición de la sociedad post-industrial. En una sociedad terciarizada, "las relaciones con el mundo exterior y con uno mismo se producen por el flujo de la comunicación masiva" (Riesman, 1964:31), lo que cambia el comportamiento de las familias, la crianza de los niños, la educación y el consumo:

Lo que es común a todos los individuos dirigidos por los otros es que sus contemporáneos constituyen la fuente de dirección para el individuo, sea los que conoce o aquellos con quienes tiene una relación indirecta, a través de amigos o de los medios masivos de comunicación. Tal fuente es, desde luego, "internalizada", en el sentido de que la dependencia con respecto a ella para una orientación en la vida se implanta temprano. Las metas hacia las cuales tiende la persona dirigida por otros varían según esa orientación: lo único que permanece inalterable durante toda la vida es el proceso de tender hacia ellas y el de prestar profunda atención a las señales procedentes de los otros ${ }^{2}$. Este modo de mantenerse en contacto con los otros permite una gran conformidad en la conducta, no a través de un ejercicio de la conducta misma, como en el carácter de dirección tradicional, sino más bien a través de una enorme sensibilidad a las acciones y deseos de los otros (RIESMAN, 1964, 32).

Se delinean así tres tipos de caracteres sociales: el dirigido por la tradición, cuya sanción en caso de incumplimiento es la vergüenza; el intradirigido, que incorpora desde pequeño una especie de "giroscopio"3 psíquico que conforma su "piloto" interno, -propenso a sentir culpa-; y el extradirigido, que no atiende sólo las enseñanzas de su familia sino también de un entorno más amplio, que capta a través de un "radar" con el que capta los deseos y expectativas cambiantes de su entorno social y cultural, y vive amenazado de una ansiedad difusa.

La educación del niño en la sociedad postindustrial es problemática. Los padres, incapaces de mostrar imágenes nítidas del sí-mismo, se muestran inseguros de cómo educar a

\footnotetext{
${ }^{2}$ Cursivas en el original.

3 También llamado "Péndulo de Foucault" es un aparato simétrico, que cuando gira alrededor de su eje de simetría, éste tiende a mantener su orientación pese a que operen sobre él otras fuerzas. El ejemplo más sencillo es el del trompo o peonza. La metáfora refiere a que, pese a las circunstancias cambiantes, el intradirigido es capaz de mantener la orientación de su "eje" valorativo. No se encuentra en una sociedad estática, como el tradicional; pero esos cambios no afectan su visión del mundo de modo automático.
} 
sus hijos, por lo que acuden especialistas o a medios de comunicación y buscan que rindan lo más posible, en todos los campos posibles. Así, el niño debe enfrentar no sólo a la exigencia de tener éxito, sino también a la de definir qué significa tener éxito" (RIESMAN, 1964:57). Estos padres:

\begin{abstract}
...inculcan en sus hijos algo así como un equipo de radar psicológico, un instrumento que no está destinado a controlar el movimiento en alguna dirección en particular mientras guía y mantiene el rumbo de una persona desde adentro, sino más bien destinado a detectar la acción simbólica, de los otros. De allí en adelante, los padres influyen en el carácter de los niños sólo en la medida en que (a) sus propias señales se mezclan con otras en el radar, (b) pueden situar a sus hijos en un determinado ambiente social a fin de modificar en grado muy limitado las señales que recibirán, (c) corren el riesgo de una censura muy parcial y precaria de los mensajes que llegan. Así, el rol de los padres disminuye en importancia comparado con el mismo rol en el grupo con dirección interna (RIESMAN, 1964:63).
\end{abstract}

La escuela también ha sufrido cambios que son resultado y causa de la aparición de esta orientación "por los otros". Más que en la individuación y el aprendizaje, los nuevos maestros se preocupan más por la socialización y la "adaptación" de los niños al grupo de pares, así como por ser, ellos mismos, aceptados por los niños, merced a la nueva horizontalidad que parece equipararlos a todos. Esta nueva escuela trasmite que más importante que los aprendizajes, es la adaptación y cooperación en un grupo, aunque esta actividad no tenga contenido alguno. La importancia de que los grupos de edades se mantengan juntos en el trayecto escolar, sin saltearse grados ni repetir, independientemente de las aptitudes y logros individuales, es una manifestación de la tendencia a la implantación de los "radares" propios de la dirección externa.

Cincuenta años más tarde, en "La sociedad individualizada" Bauman (2001) aborda el lugar de la educación en la posmodernidad, haciendo suya la distinción de Gregory Bateson entre "proto-aprendizaje" y "deutero-aprendizaje". El proto aprendizaje es un aprendizaje primario o de primer grado, y consiste en los contenidos de la instrucción. Es el resultado de lo que denominamos usualmente "educación formal": es visible, explícito, diseñado, planificado, monitorizado y registrado de modo institucionalizado. El "deutero-aprendizaje", en cambio, es un "proceso subterráneo, casi nunca consciente y todavía con menos frecuencia monitorizado por sus participantes y sólo vagamente relacionado con el tema aparente de la educación”. Pocas veces o nunca estos aprendizajes son monitoreados por los educadores, que 
permanecen ajenos a un proceso por el cual los sujetos que aprenden "adquieren habilidades incomparablemente más importantes para su vida futura" que en el proto-aprendizaje. Lo que se adquiere es:

\begin{abstract}
Un hábito de buscar contextos y secuencias de un tipo en vez de otro, un hábito de "puntuar" la corriente de los acontecimientos para producir repeticiones de un determinado tipo de frase con sentido... los estados de ánimo que denominamos "libre albedrío", pensamiento instrumental, dominio, pasividad, etc., se adquieren a través de un proceso que podemos considerar equivalente al de "aprender a aprender" (BATESON, citado por Bauman, 2001, 144).
\end{abstract}

Este "aprendizaje de segundo grado" es indispensable para que el proto-aprendizaje no genere estructuras rígidas de pensamiento y para que el sujeto sea capaz de comprender y asimilar situaciones nuevas, no incorporadas antes o variaciones de lo aprendido anteriormente. Ambos tipos de conocimiento dependen de las cualidades de los sujetos que enseñan y aprenden.

Sin embargo, un tercer tipo de conocimiento, el "aprendizaje de tercer grado", que ocurre cuando "el sujeto de la educación adquiere las capacidades necesarias para modificar la serie de alternativas que ha aprendido a esperar y a manejar en el transcurso del deuteroaprendizaje" (BAUMAN, 2001:144), depende de las características del mundo social en el cual tiene lugar. El deutero-aprendizaje tiene valor mientras los sujetos tengan "buenas razones para esperar que las contingencias con las que se encuentren se organicen en una determinada pauta estable". O sea que mientras los dos primeros tipos de aprendizaje tendrían relación con las "naturaleza humana" tal como se ha generado por la evolución de la especie, el aprendizaje de tercer grado, para Bateson tiene con frecuencia "consecuencias patógenas, que producen una personalidad apática, a la deriva, esquizofrénica" (BAUMAN, 2001, 145). Bauman construye la base de su diferenciación de las sociedades anteriores, y la nueva sociedad "posmoderna", en la distinción entre los dos primeros tipos de aprendizajes, -proto y deutero-aprendizaje- ambos adaptativos para la evolución humana como especie, y el tercer tipo con consecuencias "patológicas":

Cada uno de los puntos de orientación que hicieron que el mundo pareciera sólido y favorecieron la lógica al seleccionar las estrategias vitales (...) parecen estar en un continuo cambio. (...) Esta época nuestra destaca en el desmantelamiento de marcos 


\begin{abstract}
y en la liquidación de pautas (...). En tales circunstancias, el "aprendizaje terciario" -aprender a romper la regularidad, a liberarse de hábitos y a evitar habituarse, a reorganizar experiencias fragmentarias para que formen pautas anteriormente poco familiares a tiempo que consideran aceptables todas las pautas solamente "hasta nuevo aviso" -lejos de ser una distorsión del proceso educativo y una desviación de su verdadero objetivo, adquiere un supremo valor de adaptación y se vuelve fundamental para lo que es "indispensable para la vida". (...) El triunfo en la vida (y por tanto en la racionalidad) de los hombres y mujeres postmodernos depende de la velocidad con que consigan liberarse de viejos hábitos más que en la rápida adquisición de otros. Lo mejor de todo es no preocuparse ni lo más mínimo por la cuestión de crear pautas; el tipo de hábito que se adquiere en el "tercer aprendizaje" es el hábito de prescindir de los hábitos... (Bauman, 2001:145-146).
\end{abstract}

Además, este cambio afecta también la direccionalidad de la enseñanza y el aprendizaje. Aunque el control del deutero-aprendizaje quedaba relativamente fuera del alcance de los educadores, había entonces una distinción entre el que aprende y el que enseña, una dirección que marca desde dónde hacia dónde fluye conocimiento. Esta estructuración falta en esta etapa de la modernidad, o peor, se encuentra solapada y atravesada por una multiplicidad de otras estructuras que están claramente disociadas y dislocadas del proceso educativo tal como era entendido por la modernidad ilustrada. La tesis que Bauman (2001) explicita acá consiste en que:

\begin{abstract}
la crisis que experimentan los filósofos, los teóricos y los profesionales de la educación, en mayor o menor medida, esa versión actual de la sensación de "vivir en las encrucijadas", la búsqueda febril de una nueva autodefinición e idealmente de una nueva identidad también tienen poco que ver con los fallos o errores o la negligencia de los pedagogos profesionales o con los defectos de la teoría educativa, pero sí mucho con la fusión universal de identidades, con la desregulación y privatización de los procesos de formación de la identidad, la dispersión de las autoridades, la polifonía de mensajes de valor y el consiguiente carácter fragmentario que caracteriza el mundo en que vivimos, el mundo que prefiero llamar "posmoderno (...). La situación postmoderna ha dividido el gran juego único de la época moderna en muchos juegos pequeños y mal coordinados, ha trastocado las reglas de todos los juegos y ha acortado radicalmente la vida de cualquier serie de reglas (BAUMAN, 2001, 147-148).
\end{abstract}

Desde esta perspectiva, la crisis de la educación es "una crisis de las instituciones heredadas y de la filosofía heredada", en un mundo en el cual es vital apelar al "aprendizaje de tercer grado" para diseñar las trayectorias vitales propias. Bauman (2001) destaca acá el papel de la "autopista de la información" en la visibilización del supuesto hasta entonces indiscutido del saber académico: el monopolio de las fuentes y canales de conocimiento y su control. La revolución tecnológica hace que los hábitos adquiridos en los canales modernos 
usuales dejen de ser una ventaja y se conviertan en hándicaps, ya que acorta la vida de las capacidades útiles cuya vigencia es inferior al tiempo que lleva adquirirlas y certificarlas mediante los títulos. Así, la formación ocupacional se aleja, progresivamente, de las universidades. Esta realidad es también visible en los restantes niveles del sistema educativo. El fracaso para racionalizar la educación y coordinar sus partes significa por otro lado, la percepción del valor de adaptación del "aprendizaje terciario":

\begin{abstract}
Preparar para la vida" - esa perenne e invariable tarea de toda educación- debe significar ante todo el cultivo de la capacidad de vivir cotidianamente en paz con la incertidumbre y la ambigüedad, con una diversidad de puntos de vista y con la inexistencia de autoridades infalibles y fiables; debe significar la instilación de la tolerancia con la diferencia y la voluntad de respetar el derecho a ser diferente; debe significar el fortalecimiento de las facultades críticas y autocríticas y el valor necesario para asumir la responsabilidad por las elecciones que se hacen y sus consecuencias; debe significar la formación de la capacidad para "cambiar los marcos" y para resistir la tentación de huir de la libertad, con la ansiedad de la indecisión que acarrea junto con las alegrías de lo nuevo y lo inexplorado (BAUMAN, 2001, 158-159).
\end{abstract}

Estas habilidades, para Bauman (2001) no pueden construirse desde el deutero aprendizaje, y mucho menos del protoaprendizaje, por lo que sería imposible proponerse la planificación y el control de los procesos de enseñanza que se requieren en la sociedad de hoy, y sólo pueden surgir de este tercer grado de aprendizaje. Es, en términos de Giddens (1994), el tipo de aprendizaje que podría ser necesario en la formulación de planes fluidos de vida orientados hacia la colonización del futuro incierto en marcos de significación variables y notoriamente opacos.

\title{
Hermenéutica y análisis relacional de roles: los filmes
}

Este artículo no pretende sino esbozar algunas líneas interpretativas sobre el valor normativo que se manifiesta en algunos cuentos de hadas clásicos que han sido convertidos en filmes que, aunque mantienen sus componentes mágicos, se mantienen apegados a un realismo formal que desborda su alcance desde la audiencia infantil y familiar, hacia el público adolescente, juvenil y adulto. El abordaje interpretativo no puede incursionar acá en la intencionalidad de los actores de las historias narradas, ya que se trata de una peripecia que está al servicio de un final que se conoce de antemano, lo que la aleja por completo de la 
experiencia cotidiana de las personas en la vida cotidiana, tal como son estudiadas por la Sociología. Se trata de hacer una lectura hermenéutica del sentido objetivado en las acciones y discursos de los personajes, y en la estructura de roles generada por los mismos, así como de su relación entre dichos roles. El estudio de los rasgos psicológicos de los personajes, que suelen ser frecuentados en estudios sobre esta temática, ejemplarmente desarrollada por Bruno Bettelheim (1976), es ajeno al campo disciplinar del enfoque adoptado aquí. El foco de este breve análisis estará puesto en un momento biográficamente crucial, en relación al cual el cual la modernidad reflexiva parece plantear desafíos singulares a los actores en la conformación de su identidad: la normatividad que conforma los criterios de comportamiento y expectativas recíprocas en la formación de la primera pareja entre jóvenes hombres y mujeres. Este suele ser también el centro alrededor de la cual se desenvuelve la historia y la peripecia de sus personajes.

La enorme riqueza simbólica de cada cuento en particular, en su versión fílmica, requeriría un estudio completo, lo que excede en mucho los alcances de este trabajo, que se limitará a una visión general de ejes temáticos relevantes susceptibles de problematización, tanto en relación a su utilidad como fuentes de orientación para los espectadores o a su pertinencia como base de reflexión y de generación de sentido en contextos educativos de diverso tipo.

Y es que no es posible soslayar el contenido normativo y estructurante de los mensajes que emanan de los cuentos infantiles, como constitutivos de una tradición cultural mantenida a través de ritos como los iniciáticos a la vida adulta, los relacionados con el cortejo, el enamoramiento y la formación de pareja. Recordemos que, contrariamente a lo que es frecuente en filmes dirigidas a adultos, en todo cuento de hadas y en todo filme infantil, la historia que se narra ocurre al servicio de un final que siempre debe ser feliz. El desenlace feliz de la historia es una pieza crucial en la narración, no sólo como una culminación emocional placentera y de distensión luego de la tensión y angustia derivada de la peripecia de los personajes, sino como justificación de la corrección moral de las decisiones de los protagonistas (MARRERO, 2016). Cada decisión tomada, cada acción realizada por el personaje de identificación, en el contexto de la historia, no sólo se limita a su aspecto descriptivo, sino que, en la medida en que contribuye a que la historia fluya hacia ese final 
feliz, se inviste de un carácter normativo y moral: si el final es feliz, las decisiones tomadas fueron las correctas.

Los cuentos y los filmes de referencia para el análisis serán, según los títulos originales en inglés: Cinderella (2015) y Beauty and the Beast (2017) de Disney, Red Riding Hood (2011) de Warner Brothers, Snow White and the Huntsman (2012) de Universal y Sleeping Beauty (2014) de la productora estadounidense The Asylum. Como se aprecia, se trata de cinco cuentos clásicos de origen europeo, que cualquier lector conoce en sus versiones tradicionales recolectadas por el francés Charles Perrault o reelaboradas por los Hermanos Grimm, todos llevados al cine en la misma década, con actores reales y en escenarios realistas, aunque sin renunciar a la magia. La relevancia que han dado las productoras a estos remakes se expresa en su cuidado formal y en su reparto, en el cual participan algunas veces destacadas estrellas de la industria, como es el caso de Charlize Theron en Snow White, de Ema Watson en Beauty and the Beast, o en un despliegue muy notable, Cate Blanchett, Helena Bonham Carter y Ben Chaplin en Cinderella, dirigida por el actor y director británico Kenneth Branagh.

Todos los cuentos, excepto Caperucita Roja, giran alrededor del tópico amoroso, bajo la forma del despertar del primer amor en adolescentes, hombres o mujeres, respecto de personas del otro sexo. Lejos de cualquier ambigüedad en la definición de la propia orientación sexual, las identidades femeninas y masculinas se encuentran delineadas con claridad, y de acuerdo a los estereotipos tradicionales de género. Así, el renacer de estos cuentos puede ser interpretado, en el contexto de la expansión de la sensibilidad por la diversidad sexual, como una expresión de interés en reafirmar y reencauzar la construcción de las narrativas biográficas y de proyectos de vida alineados con modelos tradicionales recuperados del pasado, eliminando toda otra fuente de incertidumbre o desorientación, más que la que surge de modo inequívoco de la historia, respecto del rol complementario al del protagonista. Los guardianes de la tradición parecen venir a ofrecer, con estos modelos de enamoramientos exitosos ya conocidos, el confort anímico y la serenidad existencial que ha sido extirpada de la experiencia subjetiva con la radicalización de la modernidad. "No es necesario elegir una orientación sexual. Ella ya está ahí, dada. Simplemente ¡úsala!” parece sugerir, al oído atento, la notable sucesión de filmes. 
Una vez efectuada esta desambiguación inicial -las personas jóvenes se verán inevitablemente atraídas por alguien del sexo opuesto- es fácil percibir que la reelaboración de los roles tradicionales de género presentes en los filmes actuales, ha sido muy mínima. En Blancanieves y el cazador, el cuento original deriva, en el filme actual, en una historia de aventuras, con una vigorosa actividad bélica de la protagonista femenina, quien sólo pierde la conciencia durante unos pocos minutos, con el único fin, según parece, de propiciar la aparición del beso que, en los cuentos, viene a ratificar la certeza de un amor recientemente reconocido como tal.

Esta notoria alteración de la obra original, busca controvertir la principal crítica que se les ha hecho a las "princesitas": la pasividad con la que esperan ser rescatadas. En este filme se ha logrado, con creces. Filmes infantiles más recientes, como la saga de Shrek, han perpetuado y legitimado, a través del destino final de la protagonista femenina, modelos igualmente pasivos de feminidad, pese su talante aparentemente más moderno y desenfadado. Sin embargo, este es un aspecto que merece atención. ¿Qué significa, en el contexto del amor romántico, el beso en los labios de alguien que ha perdido la conciencia, -como Blancanieves o la Bella Durmiente-, o que está a punto de morir, como la Bestia, cuando Bella le besa?

Sociológicamente, el modelo de amor romántico es posterior al de amor pasión -donde predomina el arrebato y el deseo sexual- y anterior al amor "confluente" característico de la "relación pura" de la modernidad tardía, la cual "existe meramente por todo lo gratificante que ella pueda proporcionar", sin otro criterio externo al de la relación misma (GIDDENS, 1996:39). En el amor romántico:

\footnotetext{
...los afectos y lazos, el elemento sublime del amor, tienden a predominar sobre el ardor sexual. (...) El complejo del amor romántico es, a este respecto, tan inhabitual en la historia, que Max Weber lo describe como un ingrediente de la ética protestante. El amor rompe con la sexualidad a la vez que la incluye. La "virtud" asume un nuevo sentido para ambos sexos, y ya no significa sólo inocencia, sino cualidades de carácter que seleccionan a la otra persona como "especial" (GIDDENS, 2012:46).
}

Hay aquí importantes componentes de proyección de cualidades deseadas, que son vistas -o mejor, imaginadas- en la persona que es objeto del amor. Un tratado sobre familia, sexo y matrimonio en Inglaterra entre 1500 y 1800, citado por Giddens (1994), lo expresa así: 
...la noción de que hay sólo una persona en el mundo con la que uno puede unirse a todos los niveles; el carácter de esa persona se idealiza a tal punto que las faltas y defectos normales de la naturaleza humana desaparecen de la vista; el amor es como un rayo y estalla a primera vista, el amor es lo más importante del mundo, y ante él deben sacrificarse cualesquiera otras consideraciones, particularmente las consideraciones materiales; y, por último, dar rienda suelta a las emociones personales es maravilloso, no importa lo exagerada y absurda que pueda parecer la conducta resultante a los demás (GIDDENS, 1994, 117).

Una vez que esas cualidades deseadas y valiosas son reconocidas, la persona que las porta no puede sino suscitar amor. No son sus acciones lo que enamoran, sino lo que la persona es por el hecho de ser y de las cualidades que posee. Desde esta perspectiva, las niñas dormidas de los cuentos -que no siempre son princesas- o la bestia a punto de morir frente a Bella, reciben desde su pasividad involuntaria, su falta de conciencia y su exposición inerme, una aceptación total y un amor incondicional. A diferencia de los exigentes modelos de belleza y de desempeño laboral y familiar a los que están sometidos las mujeres modernas, que las obliga a una exhibición permanente de sus diferentes destrezas en las más diversas áreas, mediante una actividad sostenida a fuerza de suplementos vitamínicos, en búsqueda de algún tipo de reconocimiento o afecto, el modelo tradicional de princesa dormida -hay que reconocerlo a pesar de todo- parece más saludable. El mensaje subyacente de estos cuentos, también lo es.

La búsqueda de seguridad, autorrealización y validación externa, propio de la individuación y la igualación entre los géneros, debería separarse con nitidez de la idea de que recibir amor no es, al fin y al cabo, una cuestión que pertenezca al orden de lo meritocrático. Visto así, la oposición entre actividad y la pasividad en los modelos de comportamiento femenino y masculino, es más aparente que real. La vigilia permanente sobre el grado en que se logra la aceptación o el amor del otro, está lejos de propiciarlos, y el verse obligada a desplegar un abanico de habilidades y competencias para ser querida, no es el mejor modo de afirmar el tipo de seguridad ontológica tan necesaria y esquiva en la modernidad tardía. Un mensaje valioso para las niñas inevitablemente activas de la modernidad actual, que se desprende de estos cuentos nacidos de las entrañas de la tradición, es que no tienen por qué esforzarse en complacer al otro ni obtener desempeños notables en ningún campo, para ser merecedoras de amor y disfrutar de él. 
Además, la pasividad propiciadora de la revelación amorosa no tiene por qué descansar, exclusivamente, en el rol femenino. Como se vio, en la Bella y la Bestia, es el personaje masculino, que yace agonizante, quien recibe el beso enamorado de Bella. La pasividad exánime invita y reclama que se acepte a la persona -en este caso un ser bestial de aspecto aborrecible- por lo que él es, así como es, en su momento de mayor fragilidad e indefensión, sin promesa alguna.

A este campo en el cual se tensionan los significados originales y actuales de pasividad o actividad en los roles de género, se le superpone el de la libertad/cautiverio, planteado por el mismo filme. El despertar de la Bestia con el beso de Bella y su regreso a la apariencia humana que configura el "final feliz" de la historia, escamotea una temática que, fuera del mundo de la fantasía, constituye una opresiva realidad para millones de mujeres alrededor del mundo: el vivir sin libertad, cautivas de sus maridos, padres o hermanos, en sus propios hogares. ¿Cómo es posible el amor sin libertad?, se pregunta el personaje masculino de la historia, en el momento en que autoriza a Bella abandonar temporalmente su cautiverio. Pero el cautiverio existió, la autorización no es más que una confirmación de autoridad por parte de quien la realiza y Bella regresa a confinarse una vez más, voluntariamente, tal vez debido a un enamoramiento que ya había empezado a sentir. Lo que se presenta como el final feliz aquí, es el final de una historia que nunca debió existir, porque no puede existir final feliz para una historia en la que una niña es secuestrada y confinada. Que termine, además, enamorada, sin duda sería hoy atribuible al daño psicológico resultante de la experiencia. En muchos países donde no rigen leyes religiosas garantizadas por el estado que priven de la libertad a las mujeres, muchas siguen pidiendo permiso a sus maridos para salir, para visitar a familiares cercanos o para hacer una compra del día. La estetización de la violencia que conlleva el cautiverio en un palacio mágico y la redención del violento por el amor de su víctima, no debería poder ocultar el potencial de esta historia en la naturalización y aceptación de situaciones similares vividas en la cotidianeidad de sociedades actuales. Acá, la fuerza de un pasado tradicional cuyas pautas perviven hoy en los pliegues de la modernidad, muestra una de sus peores caras.

El lobo de Caperucita Roja es otra de ellas. El mensaje, que nos llega desde el pasado y tiene hoy una indiscutible vigencia, permite advertir a las niñas y a sus madres, que la radicalización de la modernidad no ha eliminado los peligros de la faz del mundo y que sólo 
permite un cálculo imperfecto de los riesgos. Los depredadores siguen esperando atentos, en los entornos cercanos a los hogares, la aparición de niñas conocidas, confiadas y desprevenidas, de quienes abusar y a quienes matar. Sólo una obsesión por la literalidad pudo haber hecho desaparecer al lobo del cuento como un peligro real para las mujeres, niñas y niños en el mundo, que siguen muriendo en sus manos. V.W., B.G. y F.R. fueron tres de ellos. El cuento de Caperucita Roja, truculento, con gente ingerida, regurgitada, y un animal martirizado y muerto no es afín a la extrema sensibilidad del sujeto moderno, mucho menos a la de la escuela extradirigida que describía Riesman (1964). Pero los peligros incalculables que oculta el mundo deberían poder ser revelados a los niños, para su propia protección.

\section{Conclusiones}

Experimentar la modernidad radicalizada es vivir en un mundo opaco, impulsado con fuerza arrolladora hacia un futuro incierto, dentro del cual el sujeto se ve obligado a elaborar, como mejor puede, un proyecto de vida propio. Es en esa tarea de orientarse en un mundo fragmentado en múltiples fuentes de conocimiento y significación, en el que el potencial normativo y cohesivo de la tradición llega hasta el presente para brindar criterios valorativos para orientar a las personas en unas sociedades que carecen de ellos mientras son pródigas en la producción de fuentes especializadas de conocimiento experto. La escuela no debe renegar de ese papel. La disolución de las fuentes tradicionales de autoridad y sentido, sitúan a los medios de comunicación masivos como un vehículo privilegiado para audiencias globales y difusas.

Ya no es necesario reunirse en una sala de cine para ver uno de los filmes que se comentaron más arriba, ni consultar la programación de semanal de TV: basta con conectarse a internet desde cualquier habitación, medio de transporte, o cafetería. Los cuentos de hadas tradicionales, cuyo origen, remoto, es imposible de rastrear, han sido reelaborados por una industria global, que fue capaz de detectar su pertinencia y su potencial normativo y estructurante en la solución de conflictos e incertidumbres en las que se debaten que personas singulares en los pequeños rincones del planeta. En el mundo que ha generado esta sociedad moderna, lo global y lo local se interconectan de modos múltiples y diversos. 
El universo infantil de nuestros niños y niñas es el de otros al otro lado del mundo, y es, en algún sentido, el de los personajes de cuentos de hadas con los que se identifican. En esto, sólo cabe subrayar el carácter dialéctico y tensional entre polos que pueden ser vistos como más o menos "deseables" de los modelos tradicionales y modernos de actuación femeninos y masculinos: pasividad/actividad; sujeción/libertad; confianza/riesgo. Sabiendo que no es sencillo descartar sin un examen cuidadoso el valor orientativo de los modelos en juego, este nuevo acercamiento al misterio de un mundo tradicional mágico y estable, obliga a tomarlos en serio como materia de estudio, de reflexión y por supuesto, de una transmisión mediada por el análisis crítico, a través de la educación formal.

En el contexto de opacidad y desorientación de esta modernidad, la utilización de los cuentos de hadas tendrá un lugar privilegiado en la praxis educativa, siempre que reafirmen las conquistas de los derechos de libertad e igualdad por parte de las niñas y mujeres. No obstante, una visión realista de las condiciones de vida de los niños en sociedades de hoy, obligan a reconocer que las relaciones sociales a menudo se encuentran signadas por la violencia y la depredación, de las cuales hay que enseñar a niñas y niños a precaverse.

Aunque los peligros no sean idénticos, son sí similares, a los que vivían los personajes infantiles en los cuentos de hadas tradicionales. Su regreso, sin duda, reafirma su pertinencia y oportunidad.

\section{Referências}

BAUMAN, Z. La sociedad individualizada. Madrid: Ediciones Cátedra, 2001.

BECK, U. Y BECK-GERNSHEIM, E. La individualización. Barcelona: Paidós, 2003.

BECK, U., GIDDENS, A. y LASH, S. Modernización Reflexiva: política, tradición y estética en el orden social moderno. Madrid: Alianza, 1996.

BECK, U. Teoría de la sociedad del riesgo, en Giddens et alt. 1996.

BERIAIN, J. (Comp.) Las consecuencias perversas de la modernidad. Barcelona: Anthropos, 1996.

GIDDENS, A. Modernidad y autoidentidad en Beriain, J. (Comp.) Madrid: Alianza, 1996.

GIDDENS, A. Vivir en una sociedad postradicional (1996b) en Giddens, A. et al, 1996.

GIDDENS, A. Consecuencias de la modernidad. Madrid: Alianza, 1994. 
111 Polyphonía, v. 32/2, jul./dez. 2021

GIDDENS, A. Modernidad e identidad del yo. Barcelona: Península, 1995.

GIDDENS, A. Las transformaciones de la intimidad. Madrid: Ediciones Cátedra, 2012.

MARRERO, A. Intencionalidad y destino: la falsa liberación de las mujeres en filmes infantiles recientes", $I V$ Jornadas del Centro Interdisciplinario de Investigaciones en Género, La Plata, UNLP. Disponible en: http://www.memoria.fahce.unlp.edu.ar/trab_eventos/ev.10015/ev.10015.pdf, 2016.

RIESMAN, D. La muchedumbre solitaria. Buenos Aires: Paidós, 1964. 